\title{
Prospects for the use of modern resource- saving technologies in construction and assessment of their use effectiveness on transparent insulation in the walls of buildings
}

\author{
Aleksandr Sekisov ${ }^{1, *}$, Konstantin $\mathrm{Kvetenadze}^{2}$, Anna Babich $^{2}$, Elina Fenina ${ }^{2}$, and Rustam \\ Shabanov ${ }^{2}$ \\ ${ }^{1}$ Kuban State Agrarian University named after I.T. Trubilin, 350044, Krasnodar, Russia \\ ${ }^{2}$ Kuban State Technological University, 350072, Krasnodar, Russia
}

\begin{abstract}
In recent years, the solution of the problem of saving energy resources started to be approached on a scientific basis - in an integrated and comprehensive manner. The thoughtless use of natural resources: coal, oil, gas, deforestation (the use of wood as a raw material for industry), the ever-increasing consumption of energy - all this the world's population spends for their domestic needs, and the rapidly developing industry for technical needs. This problem was aggravated by the rise in oil and gas prices by international oil concerns, which allowed them to sharply increase their profits. The so-called energy crisis broke out. Today, as never before, the question of saving energy resources and their rational use in all areas of human life arises. The purpose of this article is to study the prospects for the use of modern resource-saving technologies and assessment in construction industry.
\end{abstract}

\section{Introduction}

The research is devoted to the substantiation of scientific provisions and approaches for the technical potential development using various systems of autonomous energy supply [2,9]. For various options for autonomous heating systems for individual residential buildings, making a profit is not a goal, since the systems under study are used to meet the urgent human needs for warmth and comfort, as well as to achieve social and environmental results. Therefore, the main indicators of economic efficiency cannot always fully provide unambiguity in the choice of options under consideration. In this case, the assessment criterion can be the value of fuel costs' reduction with the same amount of heat produced due to the modernization of heat-generating equipment or a decrease in energy costs due to the improvement of the thermal insulation properties of a residential building.

* Corresponding author: alnikkss@gmail.com 


\section{Main part}

Resource-saving technologies in low-rise construction. As it is shown by our studies [2, 9], the following energy-saving technologies are currently the most promising in low-rise construction:

- use of the greenhouse effect;

- folk technologies;

- solar energy;

- wind power;

- hydropower;

- geothermal energy;

- use of ecological solid fuel boilers.

Greenhouse (grass-grown) effect - the effect of solar heat accumulation behind a stained-glass window - a consequence of the selective properties of window glass, transparent for short infrared rays of the sun and less transparent for medium and long rays, tending to return heat from the room to the environment. The additional heat-reflecting coating of the stained-glass window also has selective properties: it transmits short-wave solar radiation, while for the long-wave infrared spectrum it acts as a thermal mirror. If such a glass unit is filled with an inert gas, eliminating convection, then it will retain heat better than walls in panel houses [4]. As a result, we get great savings in heating costs.

From the popular energy saving technologies in a country house, it is also possible to recall the shutters on the windows, which were necessarily closed at night; a massive stone "Russian" stove - the warm core of the house; "Cold" outbuildings from the north and an attic that protected warm rooms from the winter cold; the use of the "heat bag" effect people climbed to sleep on the wards or on the stove under the ceiling of the hut. In a modern house, a "heat bag" can be arranged by vertical zoning of premises - at night it is warm in the bedrooms of the second floor, and cold air flows down to the first floor.

Another type of energy-saving technology is tree planting from the north and the construction of tall windbreaks. According to British ecologists, a windbreak can reduce the heat loss of a private house by $40 \%$ (in frost about 10 degrees), reducing the wind speed from 10 to $2-3 \mathrm{~m} / \mathrm{s}$. It is enough to simply save the trees on the northern side of the site when building a house [4].

Solar energy is a direction of alternative energy based on the direct use of solar radiation to obtain energy in any form. Solar energy uses a renewable energy source and is "environmentally friendly", that is, it does not generate harmful waste during the active phase of use. In low-rise buildings, energy production is carried out using solar panels. The principle of operation of solar panels is the direct conversion of sunlight into electrical current. This generates a constant current. Energy can be used directly by various DC loads, stored in batteries for later use or to cover peak loads, and converted to $220 \mathrm{~V}$ AC to power various AC loads [10].

Wind power. Wind energy is perhaps the only one that is always and everywhere. A wind generator installation that generates several kilowatts of energy per hour can fully power a residential building. To date, the payback period for such installations at $80 \%$ load is about 5 years and the service life is 20 years. Thus, by making a "prepayment" for electricity for 5 years in advance, later it will be possible to receive it for free. The only drawback of large installations is the low-frequency sound they produce, which adversely affects animals and people, but thanks to modern technology, this factor is increasingly reduced to zero, and the installation of generators with a capacity of $100 \mathrm{~kW}$ or more is prohibited in the immediate vicinity of residential buildings.

Hydropower. Mini hydroelectric power plants can become irreplaceable energy sources in sparsely populated areas, where there is no reason to pull PTL and where there are 
restrictions on the use of other energy sources. If there is a water flow with a height difference of 3 meters, a micro hydroelectric power plant can generate at least $1 \mathrm{~kW} / \mathrm{h}$, which will be enough to cover a certain amount of electricity consumption [10].

Geothermal energy is a direction of energy based on the use of thermal energy of the Earth interior for the production of electrical energy at geothermal power plants, or directly, for heating or hot water supply. The undoubted advantage of geothermal heating systems is that they can function in almost any region, regardless of the level of insolation or wind strength. Their operation requires only a rather insignificant temperature difference at the surface and in the depth of the earth, which is obtained using a fairly shallow well. The geothermal heating system practically does not require maintenance, it can serve up to a hundred years, it can work both due to the temperature difference in the ground and on the surface, and due to the temperature difference in groundwater or reservoirs [7].

Solid fuel boilers are designed for heating cottages, agricultural and industrial buildings and structures. Wastes from agricultural and woodworking industries are used as fuel in boilers: chips, shavings, sawdust, as well as pellets (granules from sawdust and wood flour). The use of huge renewable energy resources permits higher energy savings compared to traditional fuels, while significantly reducing environmental pollution [5].

\section{Evaluation of the modern resource-saving technologies use effectiveness in construction on the example of transparent insulation in the buildings' walls}

One of the most important problems in the life of a modern industrial society is the efficient use of energy resources $[2,6,8,9]$. This problem involves the solution of three interrelated tasks:

- ensuring universal access to modern energy services;

- reducing the intensity of global energy consumption;

- increase in the share of renewable energy sources.

One of the decisive factors in reducing the intensity of energy consumption is energy saving in construction $[1,3,9]$.

Let us consider a solution to the problem of energy saving through the use of transparent insulation in the walls of buildings.

Conventional thermal insulation prevents heat transfer between the external and internal environment. Transparent insulation does not interfere with the penetration of heat into the building, but rather conducts heat into an absorbing layer on the inner side of the wall.

After the sun heats the facade, the heat with some delay (usually several hours) penetrates into the building, essentially turning the wall into a large radiator. Warm walls create a more pleasant atmosphere inside the building.

Aerogel or clear plastic are used in transparent insulation. Thanks to the capillary or honeycomb structure, there is a double effect - transparency and isolation. Most of these products require window glass for protection from adverse weather conditions.

A square meter of transparent insulation can compensate for the consumption of 5-40 liters of oil per year. In energy efficient buildings, walls with such transparent insulation can reduce heating energy consumption by about $30 \%$. Renovated buildings also benefit from additional thermal insulation. The project of the school named after Paul Robson in Germany are proof of this. The prefabricated concrete building in the German city of Leipzig has shown interesting results after renovation. It was installed here $300 \mathrm{~m}^{2}$ transparent insulation, and, despite the fact that the German sun is not very active in winter, the heating regime in the cold months has not changed. Walls with conventional insulation, even after reconstruction, required $43 \mathrm{~kW}^{*} \mathrm{~h}$ of thermal energy for $1 \mathrm{~m}^{2}$ per year, and the 
walls with transparent insulation not only completely prevented energy losses, but also created a small heat gain, amounting to $2,3 \mathrm{~kW} * \mathrm{~h} / \mathrm{m}^{2}$ per year.

Automatic shading systems or architectural shading elements (balconies) are necessary to prevent overheating in summer. Because mechanical systems can malfunction, it is recommended to use simpler systems. In particular, if, in addition to transparent insulation, instead of ordinary window glass, glass with a prismatic structure and reflecting sunlight in summer is used, it is possible to achieve the same shading as a roof that protrudes 1 meter.

Transparent insulation systems are not mass-produced; therefore, their cost is much higher than the conventional insulation cost. Multilayer insulation systems that combine a transparent insulation board with translucent plaster are also relatively expensive. In addition, optimized multi-layer polycarbonate boards can be used.

New technologies for thermal insulation have spread since the early 80 s of the XX century, mainly in Germany, where the number of houses with transparent insulation is in the hundreds, and the total area of their facades is about $50000 \mathrm{~m}^{2}$. Transparent insulation will continue to play a decisive role in the construction of buildings in the future.

We will calculate the economic efficiency from the use of transparent insulation in the walls of a one-story residential building with a size of $15 \times 10$ meters and an area $150 \mathrm{~m}^{2}$. Since this technology reduces energy consumption, in order to calculate economic efficiency, it is necessary to determine the price level for $1 \mathrm{~kW}^{*} \mathrm{~h}$. In view of the fact that electricity prices differ in different regions of the country, for the calculation we will select prices for the Krasnodar Territory. The cost is 4.61 rubles $/ \mathrm{kW}^{*} \mathrm{~h}$. The height of the residential building walls is $3 \mathrm{~m}$. The number of window openings is $3(1.35 \times 1.4 \mathrm{~m})$. Number of doorways $-1(1 \times 2.1 \mathrm{~m})$.

The cost of installing classic and transparent insulation is presented in Table 1

Table 1. The cost of installing classic and transparent insulation

\begin{tabular}{|c|c|c|c|}
\hline Name & $\begin{array}{c}\text { Cost of materials, } \\
\mathrm{rub} / \mathrm{m}^{2}\end{array}$ & $\begin{array}{c}\text { The cost } \\
\text { works, } \text { rub./m² }\end{array}$ & $\begin{array}{l}\text { Total cost, } \\
\text { rub./m }\end{array}$ \\
\hline $\begin{array}{l}\text { Classical insulation } \\
\text { (Techno-nicol) }\end{array}$ & 500 & 200 & 700 \\
\hline $\begin{array}{l}\text { Transparent insulation } \\
\text { (synthetic granulate layers) }\end{array}$ & 650 & 300 & 950 \\
\hline
\end{tabular}

The cost of automatically dimming windows when installing transparent insulation $8200 \mathrm{rub} . / \mathrm{m}^{2}$.

We determine the outer walls' area:

$$
S=2 *(15+10) * 3-1 * 2.1-1.35 * 1.4 * 3=142.23 \mathrm{~m}^{2}
$$

Classical insulation device:

$$
C_{1}=700 * 142.23=99561 \mathrm{rub} .
$$

Transparent insulation device:

$$
C_{2}=950 * 142.23+8200 * 1.35 * 1.4 * 3=181612.5 \mathrm{rub} .
$$

In other words, at the initial stage, the installation of transparent insulation will cost $82,051.5$ rubles more than the classical one and 1.82 times. During operation, transparent insulation will save $30 \%$ of electricity.

We calculate the economic efficiency from the use of transparent insulation during operation and energy savings. 
Average amount of electricity consumed per year with classic insulation $-\mathrm{El}_{1}=3480$ $\mathrm{kW} * \mathrm{~h}$.

Then the average amount of electricity consumed per year with transparent insulation:

$$
E l_{2}=3480 * 0.7=2436 \mathrm{~kW}^{*} \mathrm{~h} .
$$

Electricity savings per year will be:

$$
\Delta E l=E l_{1}-E l_{2}=3480-2436=1044 \mathrm{~kW}^{*} \mathrm{~h} .
$$

Economic efficiency will be:

$$
E=1044 * 4.61=4812.84 r u b .
$$

Payback period:

$\mathrm{O}=82051.5 / 4812.84=17.0$ years is the period during which the use of this technology will pay off the difference in initial costs between transparent and classical insulation.

Due to the expensive installation of transparent insulation, the payback period is very long. Economic efficiency and payback period depends on the size of the house, floor height, number of floors, etc. It is advisable to consider the application of this technology not from the point of view of cost saving, but from the point of view of saving energy resources. Saving energy resources for one house is practically not noticeable, however, the introduction of this technology in the construction of houses throughout the country will significantly save energy resources.

This technology can only partially solve the problem of energy saving in construction. To solve this problem, an integrated approach is required, consisting in the construction of autonomous solar houses.

An autonomous solar home is a home that uses not one resource-saving technology, but several that allow it to be completely offline. Such a house can get by with solar energy all year round, even in the places with low solar activity. "Autonomy" in this case concerns not only space heating, but also hot water supply, gas for cooking, and electricity. The selfcontained building has no connection to either the electricity grid or the district heating network.

\section{Conclusion}

The use of promising energy-saving technologies in low-rise construction and, in particular, the gradual transition to autonomous solar houses will minimize the need for energy supply and reduce it to almost zero, which will make it possible to get closer to solving one of the most important problems of society - the efficient use of energy resources.

\section{References}

1. R. Nehaj, G. Molotkov, I. Rudchenko, A. Grinev, A. Sekisov, IOP Conference Series: Earth and Environmenta Science. 90, 012019 (2017) doi:10.1088/1755 $1315 / 90 / 1 / 012019$. 1315/90/1/012019/pdf, http://iopscience.iop.org/article/10.1088/1755-

2. A. Sekisov, S. Ovchinnikova, V. Grebneva, M. Chernyshova, IOP Conference Series: Materials Science and Engineering. 913, 042035 (2020) doi:10.1088/1757- 
$899 X / 913 / 4 / 042035$.

https://iopscience.iop.org/article/10.1088/1757-

$899 X / 913 / 4 / 042035 / \mathrm{pdf}$

3. A.N. Sekisov, O.G. Degtyareva, N.V. Samsonova, M.N. Grigoryan, Development of the Methods Improving the Production Costs Formation Process, International conference on Construction and Architecture: theory and practice of industry development (CATPID-2018). Trans Tech Publications, Switzerland. 931, 1210-1213 (2018) doi.org/10.4028/www.scientific.net/MSF.931.1210. https://www.scientific.net/MSF.931.1210

4. G.M. Badin, Construction and reconstruction of a low-rise energy efficient house (BHV-Petersburg, SPb, 2011)

5. T.P. Guseva, Construction 4, 4-6 (2009)

6. G.V. Degtyarev, V.E. Lebed, Polythematic network electronic scientific journal of the Kuban State Agrarian University (Scientific journal KubSAU). Krasnodar: KubSAU 03(107), 806-835 (2015)

7. A.N. Larionov, Journal of Legal and Economic Research 3, 234-238 (2014)

8. Resource-saving technologies in construction (E.M. Kalitsky et al., RIPO, Minsk, 2012)

9. A.N. Sekisov, Prospects for the introduction of modern environmentally-oriented resource-saving technologies at the regional level, Regional strategies and projects: environmental and economic aspects of development and implementation: Materials of the international scientific and practical conference. Moscow: Russian Academy of Natural Sciences. 180-186 (2020)

10. O.S. Subbotin, Vestnik MGSU. 4, 247-249 (2009) 